\title{
BMJ Open How communication can help women who experience a maternal near-miss: a qualitative study from Tanzania
}

\author{
Hilda Alinda Kwezi (D) , ${ }^{1}$ Lilian T Mselle, ${ }^{2}$ Sebalda Leshabari, ${ }^{1}$ Claudia Hanson (D) , ${ }^{3}$ \\ Andrea Barnabas Pembe ${ }^{4}$
}

To cite: Kwezi HA, Mselle LT, Leshabari S, et al. How communication can help women who experience a maternal near-miss: a qualitative study from Tanzania. BMJ Open 2021;11:e045514. doi:10.1136/ bmjopen-2020-045514

- Prepublication history and additional supplemental material for this paper are available online. To view these files, please visit the journal online (http://dx.doi.org/10.1136/ bmjopen-2020-045514)

SL deceased

Received 05 0ctober 2020 Accepted 10 0ctober 2021

Check for updates

(C) Author(s) (or their employer(s)) 2021. Re-use permitted under CC BY-NC. No commercial re-use. See rights and permissions. Published by BMJ.

${ }^{1}$ Department of Community Health Nursing, Muhimbili University of Health and Allied Sciences, Dar es Salaam,

Tanzania

${ }^{2}$ Department of Clinical Nursing, Muhimbili University of Health and Allied Sciences, Dar es Salaam, Tanzania

${ }^{3}$ Department of Public Health Sciences, Karolinska Institute, Stockholm, Sweden

${ }^{4}$ Department of Gynaecology and Obstetrics, Muhimbili University of Health and Allied Sciences, Dar es Salaam, Tanzania

Correspondence to Hilda Alinda Kwezi; khildafirstname@ymail.com

\section{ABSTRACT}

Objectives This study aimed to explore experiences of communication as an element of quality of care, among women surviving a maternal near-miss event, thus women who nearly died but survived haemorrhage, or pre-eclampsia complication during pregnancy, childbirth or within 42 days of termination of pregnancy.

Design A descriptive, phenomenological, qualitative study using semistructured interviews with women who survived a maternal near-miss in Southern Tanzania.

Setting The participants were recruited from two selected hospitals in Mtwara Region, where women sought child birth care and developed near-miss condition.

Participants Participants for this study were women who experienced and survived a maternal near-miss event and who had lived in the study area for at least 1 year. Women were recruited using an adapted version of the WHO criteria for maternal near-miss.

Data collection We identified 16 women and were able to conduct 10 in-depth interviews with women at their homes, 4 weeks after they were discharged. The interviews were audiorecorded and transcribed and translated word for word from Kiswahili. Thematic analysis was used to identify emerging themes.

Results Three major themes evolved: (1) Being informed about the care and interaction, (2) Being engaged and encouraged and (3) Being afraid to ask questions. The study highlighted that good communication with women during the provision of care helped women feel grateful, supported and cared for. Women who were unconscious during care were often not informed later of what happened. This created some negative feelings and anxiety.

Conclusion This study highlights the importance of communication, and of being informed of what happened and why. Empathetic communication with sufficient explanation on what happened and why created trust among women-a positive finding which should encourage the development of consistent approaches to strengthen healthcare provider communication skills.

\section{INTRODUCTION}

According to reports from WHO, every day in 2017, approximately 810 women died from preventable causes related to pregnancy and childbirth. ${ }^{1}$ Further, 9.5 million women are estimated to suffer from pregnancy-related

\section{STRENGTHS AND LIMITATIONS OF THIS STUDY}

$\Rightarrow$ This study explored the experience of women who survived a maternal near-miss event-a very vulnerable population.

$\Rightarrow$ Recall bias needs to be assumed, as the women were interviewed 4 weeks after the event. However, earlier interviews might have found the women still physically and emotionally distressed, which would have made the interviews impossible.

$\Rightarrow$ Some women could not be interviewed as they stayed with their close relatives living elsewhere until fully recovered from the event. This could have created selection bias, since those included might have had fewer problems or different experiences from those who were missed.

$\Rightarrow$ A main limitation of our study is that we did not include the perspectives of healthcare providers and close family members.

complications every year. ${ }^{1}{ }^{2}$ Sub-Saharan Africa alone accounts for roughly twothirds of global maternal deaths. ${ }^{1}$ Tanzania is among the countries with the highest maternal mortality rates in the world, with 398 maternal deaths per 100000 live births. ${ }^{34}$

Maternal near-miss (MNM) refers to a pregnant or delivered woman who nearly died but survived a complication during pregnancy, childbirth or within 42 days of termination of pregnancy. ${ }^{5}$ WHO proposes an 'MNM approach' to monitor and improve the quality of obstetric care, using a tool that classifies women according to several (potentially) life-threatening conditions. $^{6}$ Five potentially life-threatening conditions are used as part of the inclusion criteria set: severe postpartum haemorrhage, severe preeclampsia, eclampsia, sepsis/severe systemic infection and ruptured uterus. ${ }^{7}$

The MNM concept is promoted, as women who survive life-threatening conditions have many common aspects with those who die of such difficulties. ${ }^{8}$ They can provide insights into which aspects of quality of care need to be 
improved. ${ }^{9}$ Women who have experienced an MNM can provide valuable information on clinical, but also other aspects of care, including communication. ${ }^{10}$ Analysing MNM cases is a useful approach for designing and monitoring strategies to improve the maternal care. Women who survive life-threatening conditions share many conditions with women who died. Learning from such more positive events has been suggested to provide important clues to improve the quality of maternal care. ${ }^{11} 12$

Low quality of birth care experienced by women affects their health-seeking behaviour and trust of the healthcare system. ${ }^{13}$ According to the WHO framework for the quality of maternal and newborn healthcare, effective communication with women and their families helps women feel more involved in their care, avoids unnecessary anxiety, misunderstanding and wrong expectations, and gives women control of their condition, which contributes to a positive experience. ${ }^{14}$ In turn, effective communication among healthcare providers, relatives and women is essential to improve maternal and newborn healthcare services. ${ }^{14}$ Effective communication has been highlighted by women as a means to avoid unnecessary anxiety, misunderstandings and wrong expectations. ${ }^{15} 16$ Interpersonal communication and counselling skills, a positive attitude, plus simple, clear language that women and their families can understand, are equally important. ${ }^{17}$

When caring for women during an MNM event, healthcare providers may focus on managing the patient and provide less information about the decisions they are making. ${ }^{18}$ Therefore, in this study, we aimed to explore experiences of communication as an element of quality of care among women who had experienced an MNM in Southern Tanzania.

\section{METHOD}

\section{Setting and participants}

This qualitative, cross-sectional, descriptive study was conducted in the Mtwara region, Southern Tanzania. According to the National Bureau of Statistics, the total population of Mtwara was estimated to be $1334606 .{ }^{19}$ Mtwara region's maternal mortality ratio was estimated at 579 deaths per 100000 live births in 2012, according to the latest census, which is higher than the national maternal mortality ratio. ${ }^{19}$ This study focused on two selected hospitals that were purposefully chosen: Ligula Regional Referral Hospital, because it receives referrals from the region's surrounding districts and Mkomaindo Hospital, which is a referral centre for all health facilities within the district. These two hospitals have high caseloads, and were part of the intervention study to evaluate the impact of the Helping Mothers Survive Bleeding after Birth (HMS-BAB) training programme from 2014 to $2016 .{ }^{20}$

\section{Data collection}

Between September 2018 and October 2018, we identified women in the two hospitals using slightly modified
MNM criteria as proposed by Hanson $e t a l .^{20}$ We included women who received a transfusion of any unit of blood, reflecting the scarcity of this intervention. ${ }^{20}$ Four nursemidwives (two in each facility), who worked in the maternity wards at Ligula Regional Referral Hospital and Mkomaindo Hospital and who used to collect MNM cases during the HMS-BAB Study, ${ }^{20}$ received a 1 day refresher training to identify MNM cases. Before discharge, women with MNM were identified and invited to participate in the study. Written consent was obtained, before discharge, from all women who agreed to participate. We identified 16 women with an MNM above 18 years of age, purposely seeking a wide age range, but restricted to two key complications: haemorrhage, or pre-eclampsia and eclampsia. Our sampling approach adhered to the concept of information power, where the selected women had the most knowledge to provide the needed information for our very specific, and narrow aim. ${ }^{21}$

Home interviews were done from October 2018 to November 2018 by the first author. The interviewer reviewed the hospital-based medical records before the interview to understand the medical history. We used a semistructured interview guide informed by the WHO framework for the quality of maternal and newborn healthcare. ${ }^{14}$ The interview guide (online supplemental appendix A) included questions focusing on (1) the patient's communication with healthcare providers throughout their stay in the hospital as well as (2) the woman's involvement in decision-making on her treatment during care. Interviews were conducted at each woman's home, 4 weeks after the woman had been discharged. We were able to interview 10 of the 16 selected women while 6 women were missed as they were not at their home, but were being taken care of by their families at another place (figure 1). The interviews were conducted in a place where the woman was comfortable, and where nobody could hear the conversation between the researcher and the participant. All interviewed women were asked whether they objected to the interviews being digitally recorded. None of them objected. The interviews were conducted in Kiswahili, the national language used by all Tanzanians. Each interview lasted between 30 and 45 min and was built on the previous one, with slight modification, elaboration and better-focused questions. Data saturation was reached at the eighth interview. The last two interviews gave no new information, even with probing. There was no refusal to answer questions, nor drop-outs from this study.

\section{Data analysis}

Our analysis followed the guidance of thematic analysis proposed by Braun and Clarke. ${ }^{22}$ The transcripts were read several times to become familiar with the data and then were analysed by the first author, with frequent and substantial input from the co-authors. A process of encoding information was done in six phases, including:

1. Familiarisation with the data: the transcripts were read and reread to familiarise researchers with the 


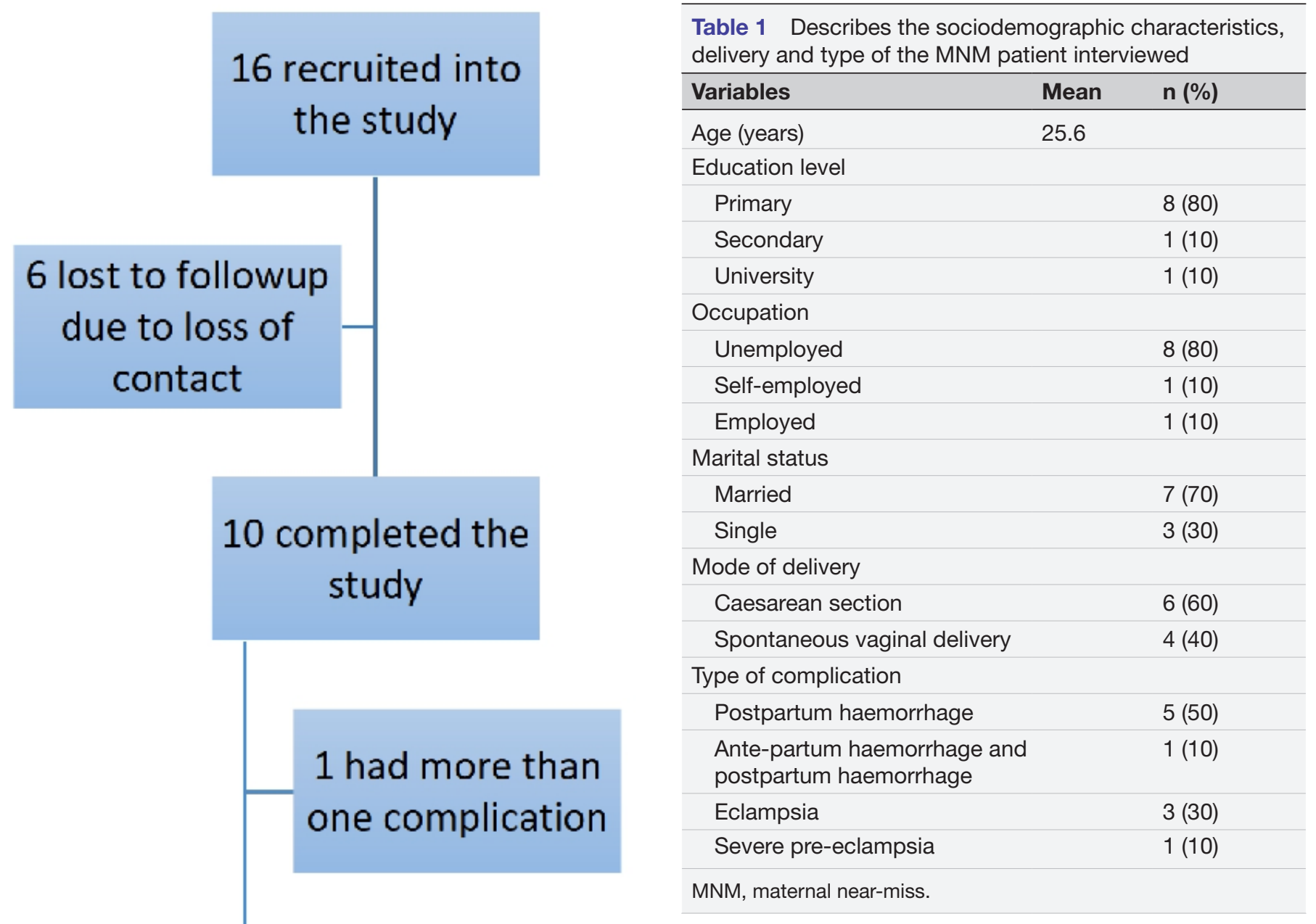

\section{9 had one complication}

Figure 1 Study flow chart. Sixteen women were selected in this study. Ten women who nearly died but survived haemorrhage, or pre-eclampsia and eclampsia completed the study with the inclusion criteria were age over 18 . Six women were missed as they were not at their home, but were being taken care of by their families at another place.

knowledge, and make sure they understood its overall meaning.

2. Generating initial codes: the entire data set was coded, and labels were generated for important information. The preliminary coding framework was based on the synthesis of initial concepts identified in previous studies. ${ }^{22}$ As the process continued, new, emerging codes were formulated and compared with the initial codes.

3. Searching for themes: the codes were combined to create sub-themes that were then condensed to generate themes.

4. Reviewing themes: sometimes, the themes were split, combined or discarded during the process.
Table 1 Describes the sociodemographic characteristics, delivery and type of the MNM patient interviewed

5. Defining and naming themes: meanings were formulated for the themes.

6. Producing the report: this involved weaving the analytical narrative and the extracts, in which vivid examples were chosen to demonstrate the essence of a point. The reporting of this qualitative study adheres to the standard for reporting qualitative research (SRQR) guidelines. ${ }^{23}$

\section{Patient and public involvement}

No patient or member of the public were involved in the design of this study.

\section{RESULTS}

Demographic characteristics of participants

A total of 10 women were interviewed. The age range was from 18 to 34 years, with a mean of 25.6 years old. Demographic characteristics, delivery and type of the MNM details of interviewed women are presented in table 1.

\section{Emerging themes}

Three major themes emerged during the analysis: ${ }^{1}$ being informed about the care and interaction, ${ }^{2}$ being engaged and encouraged, and ${ }^{3}$ being afraid to ask questions. Quotations taken directly from the data are used to illustrate the themes. 


\section{Theme 1: being informed about care and interaction}

Some women shared that they felt they were informed about their care and progress throughout pregnancy until they were discharged from the health facility after they had given birth. During antenatal visits, some of them described being counselled to seek medical care from the higher-level healthcare facility immediately for a positive labour outcome, if they noticed any danger signs. They reported that they were regularly informed about the progress of labour and its effect during the labouring process:

...the nurse who was taking care of me told me that 'you cannot deliver normally, you need to go to the theatre because your babies are in the wrong position.' I agreed, and I left there at 12:30 am to go to the theatre... (participant 1 who had PPH).

... two weeks before delivery, my body started to be swollen. I went to the hospital, and they told me that I had to go to the big hospital because these were danger signs and I should go on Monday, but on Sunday night I started to feel labor pain, so early Monday morning I went to the big hospital where I was being held in operation.(participant 2 who had eclampsia).

The women who had more severe MNM were not able to take care of themselves afterward. In some circumstances, their relatives were allowed to assist them at the health facility, and in some cases, they were informed of their patient's procedures and treatments. One woman described how her relatives were informed about her progress and care at the health facility:

...during care, they informed my relatives that they needed to provide water for me. Then my relatives responded by saying yes. They kept telling them that you need to go and buy this medicine because we don't have it here in our hospital store and my relatives agreed, and they said to them that your baby (me) had lost a lot of blood during delivery, so we need to do a blood transfusion-also agreed, and said they would pay anything .... (participant 1 who had PPH)

Other women reported being informed by nurses, midwives, and doctors about their labor progress and what was expected of them. They acknowledged that the providers listened to their concerns and dealt with them without delay:

...when I told them that I had stomach pain, they brought medication for me. When I told them that I felt the urge to defecate, they got me a pan (participant 2 who had eclampsia).

Despite being conscious, some women reported not being informed at all about the care that they received, or the procedures performed-such as catheterisation and wound dressing-and were not aware of medications they were given, nor the reasons for taking such drugs. Surprisingly, one woman, who delivered twins, reported that she was not informed that she had lost the second twin until she was at home after being discharged from the hospital, and her grandmother was the one who provided that information.

After being discharged from the hospital, when at home, my grandmother told me that I gave birth to two, but unfortunately one child died. (participant 3 who had severe pre-eclampsia).

I was seeing those bringing medicines, coming to dress wounds. They didn't tell us that "we give you this medication for these reasons". (participant 1 who had PPH).

\section{Theme 2: being engaged and encouraged}

In this study, women valued being encouraged and emotionally supported by healthcare providers during care. Some women expressed being grateful, because providers were usually present and took time to counsel, encourage and reassure them that they were in good hands, would recover and go home safely. The women we interviewed typically left pleased after receiving words of encouragement and reassurance from the healthcare providers.

.... I was often asking the doctor if my condition was normal; he told me that it was normal, and I would be okay and well.... Since I'm not a professional, I accepted that, and I know that the one who spoke it was a professional on that so that response encouraged me. (participant 9 who had eclampsia).

...they saw me as their younger sister, they advised me, and encouraged me, I mean they used to pray for me, in short, they used to pray for me for quick recovery and to return to a normal health condition for me to proceed with my daily activities (participant 10 who had PPH).

Some women were happy with the way healthcare providers supported each other and engaged with saving their life during their critical condition of MNM. A woman who had eclampsia recalled the healthcare providers' discussion and final decision on saving her life and felt grateful.

As when I had a problem like this of falling down, they all worked together to save the baby's life. They said, let's work together, no discussion, we need to help the mother in order to save her life, otherwise she can lose her life and her baby, because she can't push, she lost a lot of energy-we need to take her to the theatre... (participant 2 who had eclampsia).

After delivery, some mothers reported receiving advice from healthcare providers. Some women reported that the support and guidance received from healthcare providers was adequate and helpful. A woman with twin babies delivered by caesarean section shared her experience: 
... they (healthcare providers) came to check our wounds and tell us the progress, if the wound was not doing well, they would tell you that your wound was not doing well and they would tell you to do your best... they told us to do the exercises, they said that exercise straightens the wound. If you don't exercise, the wound will rot (oza) inside...they told us that the great support is exercise. (participant 1 who had $\mathrm{PPH})$.

Most women were happy with the way healthcare providers engaged their close family members during care. Women reported that healthcare providers engaged them and their close family members during care. Mothers and immediate family members were involved in any decision concerning themselves and their babies. They were provided with a clear explanation of the process of care.

...they asked me how I was doing and I told them that I was doing fine, they opened my eyes looking inside because I was given two units of blood. They took their equipment, which was used to measure pressure, and they measured my pressure and they told me that it was slowly coming down. (participant 5 who had eclampsia).

\section{Theme 3: being afraid to ask questions}

Women who were interviewed also indicated that the healthcare providers did not always give them the chance to ask questions or have enough time to talk with them about issues they did not understand concerning their care. When asked why those healthcare providers behaved in this way, they mentioned that some healthcare providers were too busy at their offices, showed no time for the patients and were very harsh:

Mh, you knew them very well, they act too exceptional and busy at their offices...You cannot ask them many questions because when you ask, they become very harsh. (participant 4 who had APH and $\mathrm{PPH}$ ).

Some women also had concerns about how healthcare providers communicated with them when they were in pain during labour, and how they communicated with their relatives when they were around providing support:

I would like to see those nurses change their bad behavior, they were just talking bad words. When my relatives came to help, they were chased out, or when you felt too much pain during labor, they were just talking a lot of words... so if you are very sick for sure you will feel terrible (participant 2 who had eclampsia).

Furthermore, some women were frustrated with the way healthcare providers behaved when communicating with them and so they wished to leave the hospital and go home for care:

...not always, sometimes when they decided to listen to us, they listened, others when you talked to them, they didn't even reply and left for their office. Those who come and are serious, we were afraid of them, but those who were coming while happy we couldn't be scared to ask them questions. We asked them, and indeed on my side, I asked them after surgery what kind of vegetables do we need to eat, and they explained ....others, they are not humble at all, sometimes you feel like it would be better to be discharged and return home to have a rest from this environment. (participant 5 who had eclampsia).

\section{DISCUSSION}

Our qualitative study is among the few studies that explore how women who had MNM complications experienced communication as an element of the quality of care. Our study reports that a large number of women felt informed about the care and interaction, engaged and encouraged. However, some indicated that they were afraid to ask questions and were insufficiently informed, particularly when they had periods of unconsciousness. The interviews suggest that women felt grateful, supported and cared for during the facility stay when communication was adequate. However, in some instances, women reported that healthcare providers were harsh, busy and unable or unwilling to take time to talk and listen to them, causing women to feel frustrated during their care.

Our findings are similar to other studies in low resource settings, such as one in India which found that providers shared information with the women about their condition, procedures needed and care advice. ${ }^{24}$ Generally, in our study, women trusted healthcare 'providers' knowledge, and appreciated the services and efforts to save their lives. Similar to previous research studies, women generally experienced good communication at the health facilities and appreciated the maternal services, and therefore, were satisfied with the care. ${ }^{1125}$

However, it should be noted that unconscious women were not informed sufficiently about the medication they had been on, or even the reasons for taking such medicines. This finding is similar to previous research studies in Tanzania, Ghana and Malaysia, indicating information deficits. ${ }^{2} 1826$ Adequate information including sufficient details in relation to conditions and treatment procedures, has been suggested also by others to increase the patient's adaptation process and their satisfaction. ${ }^{2} 18$

Our study also supports the conclusion of Norhayati et al from Malaysia, that family members should be allowed to accompanying the patient and remain with her. ${ }^{18}$ In our study, relatives were involved in care, decision making, and were provided with a clear explanation of the process of care in most although not all circumstances. In case relatives were well informed, these were able to inform the women experiencing the MNM complications about the care, as well as procedures performed, such as blood transfusion and caesarean sessions. Another study, done 
in Uganda, found that women's partners were eager and willing to support their women in a time of the obstetric emergency. However, they were dismayed by inadequate communication about their patient's prognosis and any implications of the childbirth complications. ${ }^{27}$

Our study reveals very positive experiences, as women reported that they received encouraging and reassuring words from healthcare providers, for example, that they would recover and go home safely. This is a support that has been highlighted as empowering in other studies. ${ }^{28} 29$ Small acts of kindness help women cope during the anxious waiting period. This was highlighted in a study from the UK: doctors and midwives repeatedly reassured women that everything was okay. These small, personal touches of reassurance from healthcare providers were perceived to help during the life threatening situation. ${ }^{30}$ Emotional support is composed of affirmative words, reassurance, showing sensitivity to the woman's fears, offering encouragement, empathy and applause for grit. All this emotional support enabled women to remain focused, consoled and gave them the courage and strength to endure the process of childbirth. ${ }^{29}$

However, we also reported negative events: some women indicated that some healthcare providers communicated with them poorly by shouting, being rude when asked for help, and exhibiting negative behaviour. This concurs with other studies reporting that women were not happy with the attitude of some nurses and midwives, and felt neglected, discriminated against, and verbally abused during care. ${ }^{13} 253132$ Burn-out, work overload, inadequate nursing staff and other resource constraints were reported to affect nurse-patient communication and their overall performance of providing quality maternal healthcare. ${ }^{133334}$ Also, in our study, some women revealed that it was difficult for them to ask healthcare providers questions during care because they were too busy at their offices. This finding is similar to the study done in Ghana, which also showed that women were unable to ask questions if the nurses and midwives had negative attitudes. ${ }^{2}$ Previous research has shown that the neglect in the facilities reinforces women's desire to deliver at home. ${ }^{13} 32$

\section{Strengths and limitations of this study}

A major strength of this study is that we explored the experiences of women who each had undergone a lifethreatening condition of similar seriousness, using the accepted definition of MNM. This provides depth and information power. ${ }^{21}$ Also we employed several measures to ensure the trustworthiness of this qualitative study. ${ }^{35}$ The study was conducted by a multi-professional team, with experience from several settings, supporting flexibility. Several authors; HAK, LTM, ABP, CH, and SL read the transcribed interviews. The first author did the initial coding and all authors discussed the themes and alternative interpretations until consensus was reached. The quality of the data was maximised by interviews being held in Kiswahili, the national language.
However, our study also has limitations, foremost the small numbers of participants, which might have limited the variation of perspectives, for example, in relation to age or socioeconomic status. However, we reached saturation after eight interviews, suggesting that our sample was sufficient for the study question. We only included participants from two public hospitals from Southern Tanzania, a typical rural setting sharing many similarities with other parts of Tanzania. Public hospitals share typically the pattern of resource constraints ${ }^{36}$ still, we cannot exclude, that women might have raised different aspects in other parts on the countries. Second, this study captured the experiences of women who had delivered several weeks earlier, and therefore, faced some recall bias. We do, however, believe that earlier interviews would have been ethically questionable and we might have found women too physically and emotionally distressed. ${ }^{37}$ The large number of women which we missed because they were cared still outside their home confirms this concern. Lastly, we only interviewed women, while interviewing healthcare providers or family members might have added additional perspectives.

\section{CONCLUSION}

This study highlights the communication issues experienced by women facing a life threatening event. The women participants shared divers positive and negative experiences. They expressed that when they were well informed, engaged, encouraged and involved by healthcare providers, this seemed to build confidence and trust in the healthcare system. Our findings also suggest that more emphasis needs to be placed on informing women who become unconscious during their stay. Training in communication and information provision should be an integral part of training to improve the quality of emergency care. Such communication training may consider the special needs of women and families where there were episode of unconsciousness.

\section{Twitter Hilda Alinda Kwezi @AlindaHilda}

Acknowledgements We would like to thank all women who participated in the study. Our great appreciation to all health workers who participated in the study. Lastly, thank you to the Swedish International Development Aid (SIDA) for funding this study as part of a Masters' training programme.

Contributors HAK, SL and CH conceptualised the study with support from ABP. HAK collected data. HAK, LTM, ABP, CH and SL performed the qualitative analysis. HAK wrote the first draft of this manuscript. All authors contributed to the manuscript development and commented on several drafts of the manuscript. All authors have read, edited and approved the final manuscript for submission.HAK is a guarantor.

Funding The Swedish International Development Cooperation Agency-SIDA funded this study through the Muhimbili University of Health and Allied Sciences, Reproductive and Child Health subprogramme.

Competing interests None declared.

Patient consent for publication Consent obtained directly from patient(s).

Ethics approval Ethical clearance was granted by the Muhimbili University of Health and Allied Sciences (MUHAS) Research and Ethical Review Board with permit number 2018-02-02/AEC/Vol.XI//261. Permission to conduct the study was obtained from the Presidential Office-Regional Administration and Local 
Government Office (PO-RALG), Regional Administrative Secretary (RAS) office, and the In-charge of Hospital offices. After they were informed of the purpose of the study, all participants provided written consent before they were discharged. Then, just before the interview at their home, the participants were asked to reaffirm their consent. The participants were informed of their right to withdraw from the study at any time, that all information they shared would be kept confidential, and that no name or other identifiers would be in the report or publication.

Provenance and peer review Not commissioned; externally peer reviewed.

Data availability statement Data are available on reasonable request. Data are available on reasonable request. All authors had access to all the data and the accuracy of the analysis.

Supplemental material This content has been supplied by the author(s). It has not been vetted by BMJ Publishing Group Limited (BMJ) and may not have been peer-reviewed. Any opinions or recommendations discussed are solely those of the author(s) and are not endorsed by BMJ. BMJ disclaims all liability and responsibility arising from any reliance placed on the content. Where the content includes any translated material, BMJ does not warrant the accuracy and reliability of the translations (including but not limited to local regulations, clinical guidelines, terminology, drug names and drug dosages), and is not responsible for any error and/or omissions arising from translation and adaptation or otherwise.

Open access This is an open access article distributed in accordance with the Creative Commons Attribution Non Commercial (CC BY-NC 4.0) license, which permits others to distribute, remix, adapt, build upon this work non-commercially, and license their derivative works on different terms, provided the original work is properly cited, appropriate credit is given, any changes made indicated, and the use is non-commercial. See: http://creativecommons.org/licenses/by-nc/4.0/.

\section{ORCID iDs}

Hilda Alinda Kwezi http://orcid.org/0000-0001-5790-1916

Claudia Hanson http://orcid.org/0000-0001-8066-7873

\section{REFERENCES}

1 "WHO", "UNICEF", "UNFPA", "WBG" and the "UNPD". Trends in 2000 to 2017 trends in maternal mortality: 2000 to 2017, 2019: 104

2 Tunçalp O, Hindin MJ, Adu-Bonsaffoh K, et al. Listening to women's voices: the quality of care of women experiencing severe maternal morbidity, in Accra, Ghana. PLoS One 2012;7:e44536.

3 Afnan-Holmes H, Magoma M, John T, et al. Tanzania's Countdown to 2015: an analysis of two decades of progress and gaps for reproductive, maternal, newborn, and child health, to inform priorities for post-2015. Lancet Glob Health 2015;3:e396-409.

4 Ministry of Health, Community Development, Gender, Elderly and Children (MoHCDGEC), Tanzania Mainland, Ministry of Health (MoH) Zanzibar, National Bureau of Statistics (NBS), Office of the Chief Government Statistician (OCGS) and ICF. 2015-16 TDHS-MIS key findings. Rockville, Maryland, USA: MoHCDGEC, MoH, NBS,OCGS and ICF, 2016.

5 Tura AK, Trang TL, van den Akker T, et al. Applicability of the who maternal near miss tool in sub-Saharan Africa: a systematic review. BMC Pregnancy Childbirth 2019;19:79.

6 Witteveen $\mathrm{T}$, Bezstarosti $\mathrm{H}$, de Koning I, et al. Validating the who maternal near miss tool: comparing high- and low-resource settings. BMC Pregnancy Childbirth 2017;17:194.

7 Pattinson R, Say L, Souza JP. Evaluating the quality of care for severe pregnancy complications: the who near-miss approach for maternal health. Bull World Health Organ 2011;87:1-29.

8 Bakshi RK, Roy D, Aggarwal P, et al. Application of WHO 'NearMiss' Tool Indicates Good Quality of Maternal Care in Rural Healthcare Setting in Uttarakhand, Northern India. J Clin Diagn Res 2016;10:10-13.

9 Hinton L, Locock L, Knight M. Maternal critical care: what can we learn from patient experience? A qualitative study. BMJ Open 2015;5:e006676.

10 Pattinson RC, Hall M. Near misses: a useful adjunct to maternal death enquiries. Br Med Bull 2003;67:231-43.

11 Kaye DK, Kakaire O, Nakimuli A, et al. Lived experiences of women who developed uterine rupture following severe obstructed labor in Mulago Hospital, Uganda. Reprod Health 2014;11:31.

12 Norhayati MN, Surianti S, Nik Hazlina NH. Metasynthesis: experiences of women with severe maternal morbidity and their perception of the quality of health care. PLoS One 2015;10:e0130452.
13 Mselle LT, Moland KM, Mvungi A, et al. Why give birth in health facility? Users' and providers' accounts of poor quality of birth care in Tanzania. BMC Health Serv Res 2013;13:174.

14 World Health Organization. Standards for improving quality of maternal and newborn care in health facilities, 2016.

15 Vedam S, Stoll K, Taiwo TK, et al. The giving voice to mothers study: inequity and mistreatment during pregnancy and childbirth in the United States. Reprod Health 2019;16:77.

16 Caswell G, Pollock K, Harwood R, et al. Communication between family carers and health professionals about end-of-life care for older people in the acute hospital setting: a qualitative study. BMC Palliat Care 2015; $14: 35$

17 Chichirez CM, Purcărea VL. Interpersonal communication in healthcare. J Med Life 2018;11:119-22.

18 Norhayati MN, Nik Hazlina NH, Asrenee AR, et al. The experiences of women with maternal near miss and their perception of quality of care in Kelantan, Malaysia: a qualitative study. BMC Pregnancy Childbirth 2017:17:1-14.

19 National Bureau of Statistics (NBS) and Office of Chief Government Statistician (OCGS) Z. Mortality and health report 2015. Natl Bur Stat Dar es Salaam 2015;1:1689-99.

20 Hanson C, Pembe AB, Alwy F, et al. Evaluating the effect of the helping mothers survive bleeding after birth (HMS BAb) training in Tanzania and Uganda: study protocol for a randomised controlled trial. Trials 2017;18:1-11.

21 Malterud K, Siersma VD, Guassora AD. Sample size in qualitative interview studies: guided by information power. Qual Health Res 2016;26:1753-60.

22 Braun V, Clarke V. Using thematic analysis in psychology using thematic analysis in psychology, 2008: 37-41.

23 Brien BCO, Harris IB, Beckman TJ. Standards for reporting qualitative research. Academic Medicine 2014;89:1245-51.

24 Bhattacharyya S, Srivastava A, Saxena M, et al. Do women's perspectives of quality of care during childbirth match with those of providers? A qualitative study in Uttar Pradesh, India. Glob Health Action 2018;11:1527971.

25 Madula P, Kalembo FW, Yu H, et al. Healthcare provider-patient communication : a qualitative study of women's perceptions during childbirth 2018:1-10.

26 Mukwenda AM, Mbekenga CK, Pembe AB, et al. Women's experiences of having had, and recovered from, eclampsia at a tertiary hospital in Tanzania. Women and Birth 2017;30:114-20.

27 Mbalinda SN, Nakimuli A, Nakubulwa S, et al. Male partners' perceptions of maternal near miss obstetric morbidity experienced by their spouses. Reprod Health 2015;12:23.

28 Afaya A, Dzomeku VM, Baku EA, et al. Women's experiences of midwifery care immediately before and after caesarean section deliveries at a public hospital in the Western region of Ghana. BMC Pregnancy Childbirth 2020;20:8

29 Lunda P, Minnie CS, Benadé P. Women's experiences of continuous support during childbirth: a meta-synthesis. BMC Pregnancy Childbirth 2018;18:167.

30 Hinton L, Locock L, Knight M. Experiences of the quality of care of women with near-miss maternal morbidities in the UK. BJOG 2014;121 Suppl 4:20-3.

31 Bohren MA, Vogel JP, Hunter EC, et al. The mistreatment of women during childbirth in health facilities globally: a mixed-methods systematic review. PLoS Med 2015;12:e1001847.

32 McMahon SA, George AS, Chebet JJ, et al. Experiences of and responses to disrespectful maternity care and abuse during childbirth; a qualitative study with women and men in Morogoro region, Tanzania. BMC Pregnancy Childbirth 2014;14:268.

33 Mkoka DA, Mahiti GR, Kiwara A, et al. "Once the government employs you, it forgets you": Health workers' and managers' perspectives on factors influencing working conditions for provision of maternal health care services in a rural district of Tanzania. Hum Resour Health 2015;13:77.

34 Kwame A, Petrucka PM. Communication in nurse-patient interaction in healthcare settings in sub-Saharan Africa: a scoping review. Int J Afr Nurs Sci 2020;12:100198.

35 Connelly LM. Trustworthiness in qualitative research. Medsurg Nurs 2016;25:435-6.

36 Alwy Al-Beity F, Pembe AB, Kwezi HA, et al. "We do what we can do to save a woman" health workers' perceptions of health facility readiness for management of postpartum haemorrhage. Glob Health Action 2020;13:1707403.

37 Norhayati MN, Nik Hazlina NH, Aniza AA. Immediate and long-term relationship between severe maternal morbidity and health-related quality of life: a prospective double cohort comparison study. BMC Public Health 2016;16:818. 